\title{
The Role of Psychosocial Risk Factors and Anxiety in Predicting Maternal and Paternal Depressive Symptomatology during Pregnancy
}

\begin{tabular}{|c|c|}
\hline Journal: & Infant Mental Health Journal \\
\hline Manuscript ID & Draft \\
\hline Wiley - Manuscript type: & Research Article \\
\hline Keywords: & $\begin{array}{l}\text { mothers, fathers, psychosocial risk factors, anxiety, antenatal depressive } \\
\text { symptoms }\end{array}$ \\
\hline Abstract: & $\begin{array}{l}\text { The aim of the present study was to investigate the role of several } \\
\text { psychosocial risk factors in predicting depressive symptomatology during } \\
\text { pregnancy in mothers and fathers, respectively. A total of } 146 \text { primiparous } \\
\text { mothers and } 105 \text { primiparous fathers reporting a psychosocial risk } \\
\text { condition were recruited independently from maternity and child health } \\
\text { services, during the second trimester of pregnancy. All parents were } \\
\text { evaluated for depressive symptomatology, anxiety and perceived social } \\
\text { support. Two hierarchical multiple regression analyses were performed to } \\
\text { determine the role of psychosocial factors in predicting antenatal } \\
\text { depressive symptomatology, in mothers and fathers. Marital } \\
\text { dissatisfaction, personal history of depression and trait anxiety were } \\
\text { identified as significant predictors of depressive symptomatology, both in } \\
\text { mothers and in fathers. Family history of substance abuse, conflictual } \\
\text { relationship with the parents in the past year, and bereavement in the past } \\
\text { year were identified as significant factors contributing to elevated } \\
\text { depressive symptoms in mothers but not fathers. In this study, several } \\
\text { psychosocial risk factors were consistently related to an increase in } \\
\text { maternal and paternal depressive symptoms during pregnancy: some of } \\
\text { these factors seem to be specifically related to maternal depressive mood. }\end{array}$ \\
\hline
\end{tabular}


Running head: PSYCHOSOCIAL RISK, ANXIETY, ANTENATAL DEPRESSION

\begin{abstract}
The aim of the present study was to investigate the role of several psychosocial risk factors in predicting depressive symptomatology during pregnancy in mothers and fathers, respectively. A total of 146 primiparous mothers and 105 primiparous fathers reporting a psychosocial risk condition were recruited independently from maternity and child health services, during the second trimester of pregnancy. All parents were evaluated for depressive symptomatology, anxiety and perceived social support. Two hierarchical multiple regression analyses were performed to determine the role of psychosocial factors in predicting antenatal depressive symptomatology, in mothers and fathers. Marital dissatisfaction, personal history of depression and trait anxiety were identified as significant predictors of depressive symptomatology, both in mothers and in fathers. Family history of substance abuse, conflictual relationship with the parents in the past year, and bereavement in the past year were identified as significant factors contributing to elevated depressive symptoms in mothers but not fathers. In this study, several psychosocial risk factors were consistently related to an increase in maternal and paternal depressive symptoms during pregnancy: some of these factors seem to be specifically related to maternal depressive mood.
\end{abstract}

Keywords: mothers, fathers, psychosocial risk factors, anxiety, antenatal depressive symptoms 
Running head: PSYCHOSOCIAL RISK, ANXIETY, ANTENATAL DEPRESSION

The Role of Psychosocial Risk Factors and Anxiety in Predicting Maternal and Paternal Depressive Symptomatology during Pregnancy

Depression is the most prevalent psychopathological disorder during pregnancy (Alipour, Lamyian, \& Hajizadeh, 2012; Bennett, Einarson, Taddio, Koren, \& Einarson, 2004), affecting from 4 to $25 \%$ of women (Teixeira, Figueiredo, Conde, Pacheco, \& Costa, 2009; Pereira, Lovisi, Pilowsky, Lima, \& Legay, 2009). Depressive symptoms are more common and more severe during pregnancy compared to the postpartum period (Evans, Heron, Francomb, Oke, \& Golding, 2001; Sidebottom, Hellerstedt, Harrison, \& Hennrikus, 2014), and occur more frequently during the first and third trimester of pregnancy, when women are facing the deep reorganising processes related to the new task of becoming mothers and when they are about to deliver (Bunevicius et al., 2009; Field, 2011; Gavin et al., 2005; Lee et al., 2007; Marchesi, Bertoni, \& Maggini, 2009; Yanikkerem, Ay, Mutlu, \& Goker, 2013). Several studies have found that antenatal depression tends to persist after childbirth with about half of postpartum depression cases continuing from pregnancy (Heron, O’Connor, Evans, Golding, \& Glover, 2004; Lee \& Chung, 2007; Leigh \& Milgrom, 2008; Marino, Battaglia, Massimino, \& Aguglia, 2012).

During the last decades, a large body of research has widely investigated maternal perinatal depression, documenting its detrimental effects on developing children, families, and long-term maternal mental health (Brennan et al., 2000; Glover, 2014; O'Connor, Heron, Golding, Beveridge, \& Glover, 2002; Previti, Pawlby, Chowdhury, Aguglia, \& Pariante, 2014; Pawlby, Hay, Sharp, Waters, \& Pariante, 2011; Plant, Pariante, Sharp, \& Pawlby, 2015; Stein et al., 2014; Van den Bergh et al., 2005).

The emerging research suggests that pregnancy is a time of increased vulnerability for the development of depression not only in women but likewise in men. Studies in this field indicate that approximately $5-10 \%$ of fathers suffer from perinatal depression (Escribà- 
Running head: PSYCHOSOCIAL RISK, ANXIETY, ANTENATAL DEPRESSION

Agüir, Gonzalez-Galarzo, Barona-Vilar, \& Artazcoz, 2008; Paulson \& Bazemore, 2010), about half the rate recorded in mothers (Bennett et al., 2004). Research has also documented that there is an increased risk for men of developing depression when their partners are in the early stages of the third trimester of pregnancy (Boyce, Condon, Barton, \& Corkindale, 2007; Condon, Boyce, \& Corkindale, 2004). With regard to the course of paternal depressive symptoms during the perinatal period, some studies have suggested that the prevalence of paternal depression decreases in the early postpartum period and then gradually increases over the child's first year (Cox, 2005; Matthey, Barnett, Ungerer, \& Waters, 2000), whereas other investigations have documented a stability of paternal depressive symptoms throughout the perinatal period (Deater-Deckard, Pickering, Dunn, \& Golding, 1998; Paulson, Bazemore, Goodman, \& Leiferman, 2016; Raskin, Richman, \& Gaines, 1990). Moreover, coherently with the literature on maternal depression, evidence on paternal depression points to increases in risks for impairments in parenting (Davis, Davis, Freed, \& Clark, 2011; Paulson, Keefe, \& Leiferman, 2009) and long-term functioning in children (Ramchandani et al., 2008).

During recent years, many studies have been carried out to identify the main risk factors involved in the development of maternal depression during pregnancy. In contrast, risk factors associated to antenatal paternal depression have received little attention from researchers.

In a systematic literature review, Lancaster and colleagues (2010) found that maternal anxiety showed one of the strongest associations with antenatal depressive symptoms. Indeed, maladaptive personality traits, such as chronic anxiety, has been proved to be a relevant risk factor for antenatal depression (Bunevicius et al., 2009; Da Costa, Larouche, Dritsa, \& Brender, 2000; Kleanthi, 2015; Moss, Skouteris, Wertheim, Paxton, \& Milgrom, 2009) and to predict pregnancy-specific anxiety across pregnancy itself (Huizink et al., 2014). In addition to maternal anxiety, Lancaster and colleagues (2010) found other relevant 
Running head: PSYCHOSOCIAL RISK, ANXIETY, ANTENATAL DEPRESSION

risk factors consistently related to an increased risk of antenatal depressive symptoms that were: negative life events, history of depression, lack of social support (particularly, lack of intimate partner support), domestic violence and unintended pregnancy. Inconsistent results were found for smoking, alcohol use, illicit drug use, parity, maternal race/ethnicity, and maternal age. No significant association was found with composite SES measures (such as the Hollingshead Index; Hollingshead, 1957) and obstetric history (i.e., spontaneous abortions, elective abortions, and foetal deaths in utero). Contrary to Lancaster and colleagues, a more recent review has identified obstetric history as a strong predictor for both depression and anxiety during pregnancy (Biaggi, Conroy, Pawlby, \& Pariante, 2016). Such review included a wider range of low-, middle- and high-income countries compared with those considered by Lancaster and colleagues (2010).

In addition, a meta-analysis of paternal depression found elevated depressive symptomatology in one partner to be significantly associated with corresponding increases in the other's (Paulson \& Bazemore, 2010). With respect to this, a very recent study has shown that mothers with prenatally depressed partners were 4.2 times more likely to have worsened depressive symptoms at 6 months postpartum than were those with prenatally non-depressed partners (Paulson et al., 2016). Contrary to the results of other studies that have identified maternal depression as a possible causal factor for paternal depression (Dudley, Roy, Kelk, \& Bernard, 2001; Schumacher, Zubaran, \& White, 2008), this study found that maternal antenatal depression did not predict changes in paternal depressive symptoms over time. In a relatively recent investigation, depressive symptomatology during pregnancy was found to be higher both in mothers and fathers who reported marital dissatisfaction and a previous history of depression (Escribà-Agüir et al., 2008). In this study, unintended pregnancy did not increase the risk of antenatal depression either in women or men; moreover, perceived low 
Running head: PSYCHOSOCIAL RISK, ANXIETY, ANTENATAL DEPRESSION

social support and partner depression were found to be associated with depression in fathers but not in mothers.

Research has also identified some relevant protective factors that mediate the impact of negative life events on maternal wellbeing during pregnancy. Among these factors, perceived social support and marital satisfaction have a significant protective role since they help the woman to face negative emotions associated with pregnancy and to prepare positively for the birth as well as the postpartum period (Evans et al., 2001; Goyal, Gay, \& Lee, 2010; Jeong et al., 2013; Lancaster et al., 2010; Lee et al., 2007; Zeng, Cui, \& Li, 2015). Moreover, active coping, high self-esteem and high self-efficacy (Edwards, Galletly, Semmler-Booth, \& Dekker, 2008; Zeng et al., 2015) have been identified as factors mediating the relationship between adverse events in life and depression (Ginsburg et al., 2008), while education has been found to contribute in reducing antenatal depression and anxiety, through the enhancement of feelings of self-worth (Nasreen, Kabir, Forsell, \& Edhborg, 2011).

While there is a growing body of scientific literature about the role of risk factors in predicting maternal depressive symptoms during pregnancy, less is known about the risk factors associated to antenatal depression in fathers. Accordingly, the aim of the present study was to investigate the psychosocial risk factors in predicting depressive symptomatology during pregnancy in mothers and fathers, respectively.

\section{Method}

\section{Participants and procedure}

Initially, 200 primiparous mothers and 179 primiparous fathers were recruited independently from maternity and child health services, during the second trimester of pregnancy: of them, only parents who reported a psychosocial risk condition were included in the study. 
Running head: PSYCHOSOCIAL RISK, ANXIETY, ANTENATAL DEPRESSION

Thus, the final sample was constituted by 146 mothers, aged between 20 and 45 years $(M=32.76 ; \pm 4.97)$ and 105 fathers, aged between 20 and 51 years $(M=35.59 ; \pm 5.97)$. The majority of parents came from middle socioeconomic status backgrounds (Hollingshead, 1957), as shown in Table 1.

Prior to data collection, parents received complete information about the study, and gave written informed consent for their participation.

\section{TABLE 1 ABOUT HERE}

\section{Measures}

Firstly, parents were interviewed using the Psychosocial Risk Interview (Ammaniti et al., 2006). This interview includes a set of questions, aimed to detect psychosocial risk factors within four main domains: risk in pregnancy, social support, parents' and family psychiatric history, and negative life events (Table 2). Items have dichotomous form ("yes" or "no"), indicating the presence or the absence of the specific risk factors. A number of psychosocial risk factors $\geq 3$ indicates psychosocial risk conditions.

\section{TABLE 2 ABOUT HERE}

Then, parents were asked to complete the Edinburgh Postnatal Depression Scale (EPDS; Cox, Holden, \& Sagovsky, 1987; Italian validation by Benvenuti, Ferrara, Niccolai, Valoriani, \& Cox, 1999), a 10-item self-report questionnaire that is widely used to screen for depressive symptoms during pregnancy and in the post-partum period. Each item is scored on a four-point scale (ranging from 0 to 3 ) and rates the intensity of depressive symptoms during the previous 7 days. Scores higher than 9 indicate "possible depression" and this cut-off score has been proved to be useful in the community screening.

Parents also completed the trait form of the State-Trait Anxiety Inventory (STAI; Spielberger, 1983; Italian validation by Pedrabissi \& Santinello, 1989), a 20-item self-report questionnaire that is applied to detect trait anxiety symptoms. Each item is scored on a four- 
Running head: PSYCHOSOCIAL RISK, ANXIETY, ANTENATAL DEPRESSION

point Likert scale (ranging from 1 to 4 ). Scores $\geq 41$ indicate clinically significant symptoms for the trait anxiety.

Finally, parents completed the Multidimensional Scale of Perceived Social Support (MSPSS; Zimet, Dahlem, Zimet, \& Farley, 1988; Italian Validation by Di Fabio \& Busoni, 2008), a 12-item scale that assesses the perceived availability of social support. Each item is scored on a seven-point scale (ranging from 1 to 7), with higher scores indicating greater levels of perceived social support. This scale provides an overall score of perceived social support as well as three subscale scores that provide measures of perceived social support from three different sources (a significant other, family, and friends). In this study, only the global measure of perceived social support was used.

\section{Data analysis}

$30.87 \%$ of mothers $(\mathrm{N}=45)$ and $17.1 \%$ of fathers $(\mathrm{N}=18)$ reported scores on the EPDS of $\geq 9$, thus indicating the presence of depressive symptomatology. The mean score for EPDS was $12.22( \pm 3.02$; range $9-21)$ in mothers and $10.94( \pm 2.16$, range $9-15)$ in fathers, respectively.

Chi-square and Pearson correlations were performed in order to explore the relationships between individual demographic and psychosocial independent variables (categorical and continuous) and the dependent variable (that is, depressive symptomatology).

Two hierarchical multiple linear regressions (for mothers and fathers, respectively) were performed to test the relationships between the independent variables that were significant at a 0.05 significance level and the dependent variable.

\section{Results}

Chi square analyses evidenced that the following psychosocial variables were more represented in mothers suffering from depressive symptoms: risk in pregnancy (unplanned or 
Running head: PSYCHOSOCIAL RISK, ANXIETY, ANTENATAL DEPRESSION

unwanted pregnancy); social support (marital dissatisfaction); psychiatric history (personal history of depression, and family history of substance abuse); negative life events (conflictual relationship with parents in the past year, parental separation during childhood; bereavement in the past year) (Table 3).

\section{TABLE 3 ABOUT HERE}

In fathers, Chi square analyses evidenced a significant relationship between a restricted set of psychosocial independent (categorical) variables and depressive symptomatology: specifically, marital dissatisfaction (for the domain social support); personal history of depression, partner's history of depression, and partner's history of anxiety (for the domain psychiatric history); conflictual relationship with parents in the last year (for the domain negative life events) (Table 4).

\section{TABLE 4 ABOUT HERE}

Correlational analyses were performed in order to explore the relationship between psychosocial independent (continuous) variables and depressive symptomatology, both in mothers and in fathers. As shown in Table 5, both mothers and fathers with higher scores on EPDS perceived a lower social support and had a higher level of trait anxiety. With respect to sociodemographic variables, in mothers, depressive symptomatology and age were negatively related (with younger mothers reporting higher scores on EPDS); while neither mothers nor fathers reported significant correlations between scores on EPDS and the Hollingshead Two Factor Index of Social Position.

\section{TABLE 5 ABOUT HERE}

Two hierarchical multiple regression analyses (for mothers and fathers, respectively) were performed to determine the role of the antenatal psychosocial factors that were significant in bivariate analyses at a 0.05 significance level in predicting depressive symptomatology during pregnancy, in mothers and fathers, respectively. 
Running head: PSYCHOSOCIAL RISK, ANXIETY, ANTENATAL DEPRESSION

Five steps were conducted in the first hierarchical multiple regression analyses, entering: age (first block); variables related to pregnancy risk factors (second block); variables related to social support (third block); variables related to psychiatric history (fourth block); variables related to negative life events (fifth block) (Table 6).

\section{TABLE 6 ABOUT HERE}

In the first step, the model $\mathrm{R}^{2}$ was equal to 0.05 , thus suggesting that only $5 \%$ of the variance in depressive symptomatology was explained by this demographic variable $\left[\mathrm{F}_{(1,144)}\right.$ $=8.004 ; \mathrm{p}=.005]$. When the additional factor (Unplanned or unwanted pregnancy) was added, the model explained $10 \%$ of the variance $\left[\mathrm{F}_{(2,143)}=7.649 ; \mathrm{p}=.001\right]$. In this stage both age $(\beta=-.19, \mathrm{p}=.024)$ and Unplanned or unwanted pregnancy $(\beta=.21, \mathrm{p}=.009)$ were identified as significant predictors of depressive symptomatology in mothers. When variables related to social support were added, the model was improved significantly $\left[\mathrm{F}_{(4,141)}=12.734\right.$; $\mathrm{p}=.000]$ and an additional $17 \%$ of the variance in depressive symptomatology was explained. Specifically, age $(\beta=-.17, p=.022)$, marital dissatisfaction $(\beta=-.32, p=.000)$, and perceived social support $(\beta=-.22, \mathrm{p}=.003)$ were identified as significant in predicting maternal depressive symptoms during pregnancy. The addition of the variables related to social support rendered unplanned or unwanted pregnancy non-significant. In the fourth step, the introduction of psychiatric history variables significantly improved the model $\left[\mathrm{F}_{(7,138)}=\right.$ $23.150 ; \mathrm{p}=.000 \mathrm{]}$ and a further $28 \%$ of the variance was explained. Marital dissatisfaction ( $\beta$ $=.28 ; \mathrm{p}=.000)$, personal history of depression $(\beta=.16 ; \mathrm{p}=.011)$, trait anxiety $(\beta=.46, \mathrm{p}=$ $.000)$, and family history of substance abuse $(\beta=.16, \mathrm{p}=.011)$ were identified as significant predictors of maternal depressive symptomatology. The added psychopathological variables rendered age and perceived social support non-significant. In the fifth step, the inclusion of negative life events significantly improved the model $\left[\mathrm{F}_{(10,135)}=19.928 ; \mathrm{p}=.000\right]$, even though these variables explained only an additional $5 \%$ of the variance. In this step, marital 
Running head: PSYCHOSOCIAL RISK, ANXIETY, ANTENATAL DEPRESSION

dissatisfaction $(\beta=.23 ; p=.000)$, personal history of depression $(\beta=.13 ; p=.033)$, trait anxiety $(\beta=.45, \mathrm{p}=.000)$, family history of substance abuse $(\beta=.15, \mathrm{p}=.015)$, conflictual relationship with parents in the past year $(\beta=.17, \mathrm{p}=.005)$, and bereavement in the past year $(\beta=.12, \mathrm{p}=.032)$ were identified as significant predictors of depressive symptomatology in mothers, and explained $59 \%$ of variance in EPDS scores.

Table 7 shows the output of the hierarchical multiple regression analysis that was performed in order to explore the role of psychosocial risk factors in predicting depressive symptomatology in fathers.

\section{TABLE 7 ABOUT HERE}

In the first step, marital dissatisfaction and perceived social support were entered. In the second step, psychopathological variables were added to the model (personal history of depression, trait anxiety, partners' history of depression, and partners' history of anxiety).

The first step explained $19 \%$ of variance in EPDS scores $\left[\mathrm{F}_{(2,103)}=11.721 ; \mathrm{p}=.000\right]$. Specifically, both marital dissatisfaction $(\beta=.29 ; p=.003)$ and perceived social support $(\beta=$ $-.22 ; \mathrm{p}=.025)$ were identified as significant predictors of depressive symptoms in fathers. When all predictors were included in the model (including psychiatric variables), an additional $23 \%$ of variance in paternal depressive symptomatology was explained $\left[\mathrm{F}_{6,99)}=\right.$ 11.808; $\mathrm{p}=.000]$. In this second step, marital dissatisfaction $(\beta=.19 ; \mathrm{p}=.035)$, personal history of depression $(\beta=.17 ; p=.038)$, and trait anxiety $(\beta=.37 ; p=.000)$ were identified as significant factors contributing to elevated depressed symptoms in fathers, while perceived social support could no longer be identified as a significant predictor. All the independent variables explained $42 \%$ of the variations in EPDS scores in fathers.

\section{Discussion}

During pregnancy, mothers and fathers have to face deep reorganising processes related to the new task of becoming parents; such significant processes are aimed to form an 
Running head: PSYCHOSOCIAL RISK, ANXIETY, ANTENATAL DEPRESSION

emotional bond with the child which provides scaffolding for his/her subsequent development (Ammaniti, Trentini, Menozzi, \& Tambelli, 2014). By virtue of these complex transformations, pregnancy represents a relevant developmental transition with significant implications for both parents. The complex interpersonal adjustments associated with the new responsibilities and demands that occur during pregnancy can negatively affect the individuals' functioning, putting the parents at risk for a wide range of psychopathological disorders, among which depression is the most represented (Alipour et al., 2012; Bennett et al., 2004; Boyce et al., 2007).

Despite the large body of research focused on investigating the main risk factors involved in the development of maternal depressive symptomatology during pregnancy, much less is known about the risk factors associated to antenatal paternal depressive mood.

In line with these premises, this study aimed to explore the psychosocial risk factors that predict antenatal depressive symptomatology in mothers and fathers, respectively.

First of all, in line with previous investigations, we found that depressive symptomatology during pregnancy was higher in mothers than in fathers (Bennett et al., 2004; Escribà-Agüir et al., 2008; Paulson \& Bazemore, 2010). It has been suggested that these gender differences may be due to a possible underestimation of paternal depressive conditions. Indeed, men display different depressive symptoms from women: such peculiarities are often unrecognised since most of the studies on antenatal paternal depression have been carried out by using self-report questionnaires or diagnostic interviews developed for assessing depressive symptomatology in mothers (Kim \& Swain, 2007; Matthey et al., 2000).

In this study, while risk factors related to lack of intimate support and psychopathology were found to be consistently related to an increase in antenatal depressive symptoms both in 
Running head: PSYCHOSOCIAL RISK, ANXIETY, ANTENATAL DEPRESSION

mothers and fathers, negative life events were found to predict only maternal depressive mood during pregnancy.

Coherently with previous findings (Escribà-Aguir et al., 2008), marital dissatisfaction was strongly associated with antenatal depressive mood, both in mothers and in fathers. This result is particularly relevant if we consider the role of marital intimate relationship in mediating the impact of negative life events on parental wellbeing during pregnancy and in preparing positively for childbirth as well as the postpartum period (Evans et al., 2001; Goyal et al., 2010; Jeong et al., 2013; Lancaster et al., 2010; Lee et al., 2007; Zeng et al., 2015).

Among psychopathological risk factors, antenatal depressive symptomatology was predicted by trait anxiety and personal history of depression, both in mothers and in fathers. These findings are consistent with those of previous research studies in which a strong association between trait anxiety (as a stable personality trait) and antenatal depression has been documented (Bunevicius et al., 2009; Da Costa et al., 2000; Kleanthi, 2015; Moss et al., 2009).

An interesting result was found in relation to family history of substance abuse, which predicted antenatal depressive symptomatology in mothers but not in fathers. A large body of research has documented the effects of parental high risk behaviours on individuals' development. Substance (alcohol and drug) abuse is thought to be a major risk factor for the perpetration (Dubowitz et al., 2011; Ondersma, 2002) and recurrence (Jonson-Reid, Chung, Way, \& Jolley, 2010) of child maltreatment and emotional neglect. Parents with substance use disorders often fail in regulating emotions and controlling anger and impulsivity; they do not respond sensitively to the child's cues and needs and expose the child to a chaotic and unpredictable living environment (Chaplin \& Sinha, 2013; Dube et al., 2001; Hanson et al., 2006). The association between the experience of child maltreatment and the later development of depression has been largely documented (Comijs et al., 2007; Green et al., 
Running head: PSYCHOSOCIAL RISK, ANXIETY, ANTENATAL DEPRESSION

2010; Nanni, Uher, \& Danese, 2012; Norman et al., 2012; Staton-Tindall, Sprang, Clark, Walker, \& Craig, 2013; Widom, DuMont, \& Czaja, 2007). It has been suggested that childhood adversities (such as exposure to parental substance abuse) increase a stress sensitivity that persists into adulthood, making individuals especially vulnerable to mental disorders triggered by adult stressors (Hammen, Henry, \& Daley, 2000; Kendler, Kuhn, \& Prescott, 2004). It has been evidenced that women with early exposure to adversities are more likely to become depressed following stress than women without such early negative experiences (Hammen et al., 2000): this aspect is particularly relevant during pregnancy, when women have to cope with the stress coming from the dramatic reorganisation of personal identity.

Some interesting differences were found between psychosocial risk factors associated to depressive condition in mothers and fathers.

In this study, relevant negative life events experienced during the past year (specifically, conflictual relationship with parents in the past year and bereavement) were identified as significant predictors of depressive symptomatology in mothers but not in fathers. These results may confirm that, compared to men, women who had early relational adversities, are more vulnerable to depressive symptoms when faced with negative life experiences (Hammen et al., 2000; Kendler et al., 2004).

It is important to underline that during pregnancy the woman has to reorganise her internal representational world, facing and elaborating her relationship with her own parents (especially the mother), because she is not only a daughter in relation to them, but she is experiencing the chance to become a parent too, giving way to an identification with them (in particular, with the mother) (Pines, 1972). Pregnancy may be characterised by conflicts and ambivalence, especially if the woman is experiencing an emotional unavailability or rejection from her own parents. In line with this, research has largely documented that women who 
Running head: PSYCHOSOCIAL RISK, ANXIETY, ANTENATAL DEPRESSION

perceive their families as emotionally unavailable and unsupportive appear more likely to experience depression during pregnancy as well as in the postpartum period (Robertson, Grace, Wallington, \& Stewart, 2004). Interestingly, there is some evidence to suggest that family support is more important than intimate partner support among women who experience depressive symptomatology during the perinatal period (Haslam, Pakenham, \& Smith, 2006).

In this study, no association has been found between maternal age, unplanned or unwanted pregnancy and antenatal depressive mood. These results are in line with those evidenced by Lancaster and colleagues (2010) and by Escribà-Agüir and colleagues (2008), that have evidenced the inconsistent findings concerning the role of these variables in predicting depressive symptomatology during pregnancy, especially with respect to unintended pregnancy (Biaggi et al., 2016).

The major limitation of this study is its observational design which leaves inferences about the causal direction of the effect of psychosocial and psychopathological factors on maternal and paternal depressive symptomatology during pregnancy. Indeed, it is not possible to establish whether depressed symptomatology was present prior to pregnancy and for how long, or whether onset was actually during pregnancy. Moreover, it is not known whether the factors associated with pregnancy depressive mood (particularly marital dissatisfaction) occurred before or after the depressive period. Considering the detrimental consequences of maternal and paternal perinatal depressive condition on parenting and child development, a follow-up study should be implemented to monitor the stability of maternal and paternal depressive symptomatology across time. Results coming from such investigations may be efficiently used in the field of early intervention programmes, aimed to promote functional parenting and to empower positive relational experiences within the family. 
Running head: PSYCHOSOCIAL RISK, ANXIETY, ANTENATAL DEPRESSION

A further constraint of this study is the absence of information about women's and men's expectations and fears related to childbirth and postpartum period adjustment. These aspects could have provided a wider knowledge of the factors that are implicated in antenatal depressive mood and (through a prospective investigation) of their possible association with postpartum depressive symptomatology.

Moreover, in this study, pregnant mothers and fathers were recruited independently from maternity and child health services. This excluded the possibility to assess whether depressive symptomatology in one partner was associated with corresponding increases in the other's. Considering the evidenced association between partners' depressive symptoms (Paulson \& Bazemore, 2010), further investigations are needed to examine maternal and paternal depressive symptomatology during the perinatal period by including measures of both partners. 


\section{Running head: PSYCHOSOCIAL RISK, ANXIETY, ANTENATAL DEPRESSION}

\section{References}

Alipour, Z., Lamyian, M., \& Hajizadeh, E. (2012). Anxiety and fear of childbirth as predictors of postnatal depression in nulliparous women. Women Birth, 25, e37-e43. https://doi.org/10.1016/j.wombi.2011.09.002

Ammaniti, M., Speranza, A. M., Tambelli, R., Muscetta, S., Lucarelli, L., Vismara, L., ... Cimino, S. (2006). A prevention and promotion intervention program in the field of mother-infant relationship. Infant Mental Health Journal, 27(1), 70-90. doi:10.1002/imhj.20081

Ammaniti, M., Trentini, C., Menozzi, F., \& Tambelli, R. (2014). Transition to parenthood: studies of intersubjectivity in mothers and fathers. In R. N. Emde \& M. Leuzinger-Bohleber (Eds.), Early parenting and prevention of disorder: Psychoanalytic research at interdisciplinary frontiers (pp. 129-164). London: Karnac Books.

Bennett, H. A., Einarson, A., Taddio, A., Koren, G., \& Einarson, T.R. (2004). Prevalence of depression during pregnancy: Systematic review. Obstetrics \& Gynecology. 103(4), 698-709. doi:10.1097/01.AOG.0000116689.75396.5f

Benvenuti, P., Ferrara, M., Niccolai, C., Valoriani, V., \& Cox, J. L. (1999). The Edinburgh postnatal depression scale: Validation for an Italian sample. Journal of Affective Disorders, 53(2), 137-141. https://doi.org/10.1016/S0165-0327(98)00102-5

Biaggi, A., Conroy, S., Pawlby, S., \& Pariante, C. M. (2016). Identifying the women at risk of antenatal anxiety and depression: A systematic review. Journal of Affective Disorders, 191, 62-77. doi:10.1016/j.jad.2015.11.014

Boyce, P., Condon, J., Barton, J., \& Corkindale, C. (2007). First-time fathers' study: Psychological distress in expectant fathers during pregnancy. Australian \& New Zealand Journal of Psychiatry, 41(9), 718-725. Retrieved from http://www.tandfonline.com/doi/abs/10.1080/00048670701517959?src=recsys\&journalCode $=$ ianp20

Brennan, P. A., Hammen, C., Andersen, M. J., Bor, W., Najman, J. M., \& Williams, G. M. (2000). Chronicity, severity, and timing of maternal depressive symptoms: Relationships with child outcomes at age 5. Developmental Psychology, 36(6), 759-766. doi:10.1037//0012-1649.36.6.759

Bunevicius, R., Kusminskas, L., Bunevicius, A., Nadisauskiene, R. J., Jureniene, K., \& Pop, V. J. (2009). Psychosocial risk factors for depression during pregnancy. Acta Obstetricia et Gynecologica Scandinavica, 88(5), 599-605. doi:10.1080/00016340902846049

Chaplin, T. M., \& Sinha, R. (2013). Stress and parental addiction. In N. E. Suchman, M. Pajulo \& L. C. Mayes (Eds.), Parenting and substance abuse: Developmental approaches to intervention (pp. 24-43). Oxford, UK: Oxford University Press.

Comijs, H. C., Beekman, A. T., Smit, F., Bremmer, M., Van Tilburg, T., \& Deeg, D. J. (2007). Childhood adversity, recent life events and depression in late life. Journal of Affective Disorders, 103(1), 243-246. https://doi.org/10.1016/j.jad.2007.01.012

Condon, J. T., Boyce, P., \& Corkindale, C. J. (2004). The firsttime fathers study: A prospective study of the mental health and wellbeing of men during the transition to parenthood. Australian and New Zealand Journal of Psychiatry, 38(1 $\square 2)$, 56-64. doi:10.1111/j.14401614.2004.01298.x

Cox, J. (2005). Postnatal depression in fathers. Lancet, 366(9490), 982. http://dx.doi.org/10.1016/S0140-6736(05)67372-2

Cox, J. L., Holden, J. M., \& Sagovsky, R. (1987). Detection of postnatal depression. Development of the 10-item Edinburgh Postnatal Depression Scale. The British Journal of Psychiatry, 150(6), 782-786. doi:10.1192/bjp.150.6.782

Da Costa, D., Larouche, J., Dritsa, M., \& Brender, W. (2000). Psychosocial correlates of prepartum and postpartum depressed mood. Journal of Affective Disorders, 59(1), 31-40. doi:10.1016/S0165-0327(99)00128-7

Davis, R. N., Davis, M. M., Freed, G. L., \& Clark, S. J. (2011). Fathers' depression related to positive and negative parenting behaviors with 1-year-old children. Pediatrics, 127(4), 612-618. doi:10.1542/peds.2010-1779

Deater-Deckard, K., Pickering, K., Dunn, J. F., \& Golding, J. (1998). Family structure and depressive symptoms in men preceding and following the birth of a child. The Avon Longitudinal Study of Pregnancy, \& Childhood Study Team. American Journal of Psychiatry, 155(6), 818-823. doi:10.1176/ajp.155.6.818

Di Fabio, A., \& Busoni, L. (2008). Misurare il supporto sociale percepito: Proprietà psicometriche della Multidimensional Scale of Perceived Social Support (MSPSS) in un campione di studenti universitari. Risorsa Uomo, 14(3), 339-350. Retrieved from https://www.francoangeli.it/riviste/Scheda_rivista.aspx?IDArticolo=34109

Dube, S. R., Anda, R. F., Felitti, V. J., Chapman, D. P., Williamson, D. F., \& Giles, W. H. (2001). Childhood abuse, household dysfunction, and the risk of attempted suicide throughout the life span: Findings from the Adverse Childhood Experiences Study. Journal of the American Medical Association, 286(24), 3089-3096. doi:10.1001/jama.286.24.3089

Dubowitz, H., Kim, J., Black, M. M., Weisbart, C., Semiatin, J., \& Magder, L. S. (2011). Identifying children at high risk for a child maltreatment report. Child Abuse \& Neglect, 35(2), 96-104. https://doi.org/10.1016/j.chiabu.2010.09.003

Dudley, M., Roy, K., Kelk, N., \& Bernard, D. (2001). Psychological correlates of depression in fathers and mothers in the first postnatal year. Journal of Reproductive and Infant Psychology, 19(3), 187-202. Retrieved from http://www.tandfonline.com/doi/abs/10.1080/02646830124397

Edwards, B., Galletly, C., Semmler-Booth, T., \& Dekker, G. (2008). Does antenatal screening for psychosocial risk factors predict postnatal depression? A follow-up study of 154 women in Adelaide, South Australia. Australian \& New Zealand Journal of Psychiatry, 42(1), 51-55. doi:10.1080/00048670701739629

Escribà-Agüir, V., Gonzalez-Galarzo, M. C., Barona-Vilar, C., \& Artazcoz, L. (2008). Factors related to depression during pregnancy: Are there gender differences? Journal of Epidemiology \& Community Health, 62(5), 410-414. doi:10.1136/jech.2007.063016

Evans, J., Heron, J., Francomb, H., Oke, S., \& Golding, J. (2001). Cohort study of depressed mood during pregnancy and after childbirth. British Medical Journal, 323, 257-260. https://doi.org/10.1136/bmj.323.7307.25

Field, T. (2011). Prenatal depression effects on early development: A review. Infant behavior and development, 34(1), 1-14. https://doi.org/10.1016/j.infbeh.2010.09.008

Gavin, N. I., Gaynes, B. N., Lohr, K. N., Meltzer-Brody, S., Gartlehner, G., \& Swinson, T. (2005). Perinatal depression: A systematic review of prevalence and incidence. Obstetrics \& Gynecology, 106(5, Part 1), 1071-1083. doi:10.1097/01.AOG.0000183597.31630.db

Ginsburg, G. S., Baker, E. V., Mullany, B. C., Barlow, A., Goklish, N., Hastings, R., ... Walkup, J. (2008). Depressive symptoms among reservation-based pregnant American Indian adolescents. Maternal and Child Health Journal, 12(1), 110-118. doi:10.1007/s10995-008-0352-2

Glover, V. (2014). Maternal depression, anxiety and stress during pregnancy and child outcome: What needs to be done. Best Practice \& Research Clinical Obstetrics \& Gynaecology, 28(1), 25-35. https://doi.org/10.1016/j.bpobgyn.2013.08.017

Goyal, D., Gay, C., \& Lee, K. A. (2010). How much does low socioeconomic status increase the risk of prenatal and postpartum depressive symptoms in first-time mothers? Women's Health Issues, 20(2), 96-104. https://doi.org/10.1016/j.whi.2009.11.003

Green, J. G., McLaughlin, K. A., Berglund, P. A., Gruber, M. J., Sampson, N. A., Zaslavsky, A. M., \& Kessler, R. C. (2010). Childhood adversities and adult psychiatric disorders in the national comorbidity survey replication I: Associations with first onset of DSMIV disorders. Archives of General Psychiatry, 67(2), 113-123. doi:10.1001/archgenpsychiatry.2009.186

Hamman, C., Henry, R., \& Daley, S. E. (2000). Depression and sensitization to stressors among young women as a function of childhood adversity. Journal of Consulting and Clinical Psychology, 68(5), 782-787. doi:10.1037//0022-006X.68.5.782 


\section{Running head: PSYCHOSOCIAL RISK, ANXIETY, ANTENATAL DEPRESSION}

Hanson, R. F., Self-Brown, S., Fricker-Elhai, A. E., Kilpatrick, D. G., Saunders, B. E., \& Resnick, H. S. (2006). The relations between family environment and violence exposure among youth: Findings from the National Survey of Adolescents. Child Maltreatment, 11(1), 3-15. https://doi.org/10.1177/1077559505279295

Haslam, D. M., Pakenham, K. I., \& Smith, A. (2006). Social support and postpartum depressive symptomatology: The mediating role of maternal self $\square$ efficacy. Infant Mental Health Journal, 27(3), 276-291. doi:10.1002/imhj.20092

Heron, J., O'Connor, T. G., Evans, J., Golding, J., Glover, V., \& ALSPAC Study Team. (2004). The course of anxiety and depression through pregnancy and the postpartum in a community sample. Journal of Affective Disorders, 80(1), 65-73. https://doi.org/10.1016/j.jad.2003.08.004

Hollingshead, A. B. (1957). Two Factor Index of Social Position. Mimeo. New Haven, CT: Yale University.

Huizink, A. C., Menting, B., Oosterman, M., Verhage, M. L., Kunseler, F. C., \& Schuengel, C. (2014). The interrelationship between pregnancy-specific anxiety and general anxiety across pregnancy: A longitudinal study. Journal of Psychosomatic Obstetrics \& Gynecology,_35(3), 92-100. http://dx.doi.org/10.3109/0167482X.2014.944498

Jeong, H. G., Lim, J. S., Lee, M. S., Kim, S. H., Jung, I. K., \& Joe, S. H. (2013). The association of psychosocial factors and obstetric history with depression in pregnant women: Focus on the role of emotional support. General Hospital Psychiatry, 35(4), 354-358. https://doi.org/10.1016/j.genhosppsych.2013.02.009

Jonson-Reid, M., Chung, S., Way, I., \& Jolley, J. (2010). Understanding service use and victim patterns associated with re-reports of alleged maltreatment perpetrators. Children and Youth Services review, 32(6), 790-797. https://doi.org/10.1016/j.childyouth.2010.01.013

Kendler, K. S., Kuhn, J. W., \& Prescott, C. A. (2004). Childhood sexual abuse, stressful life events and risk for major depression in women. Psychological Medicine, 34(8), 1475-1482. https://doi.org/10.1017/S003329170400265X

Kim, P., \& Swain, J. E. (2007). Sad dads: Paternal postpartum depression. Psychiatry (Edgmont), 4(2), 35. Retrieved from https://www.ncbi.nlm.nih.gov/pmc/articles/PMC2922346/

Kleanthi, G. (2015). Psychosocial risk factors of depression in pregnancy: A survey study. Health Science Journal, 9, 1-11. Retrieved from http://www.hsj.gr/medicine/psychosocial-risk-factors-of-depression-in-pregnancy-asurvey-study.pdf

Lancaster, C. A., Gold, K. J., Flynn, H. A., Yoo, H., Marcus, S. M., \& Davis, M. M. (2010). Risk factors for depressive symptoms during pregnancy: A systematic review. American Journal of Obstetrics and Gynecology, 202(1), 5-14. doi:10.1016/j.ajog.2009.09.007

Lee, A. M., Lam, S. K., Lau, S. M., Chong, C. S. Y., Chui, H. W., \& Fong, D. Y. T. (2007). Prevalence, course, and risk factors for antenatal anxiety and depression. Obstetrics \& Gynecology, 110(5), 1102-1112. doi:10.1097/01.AOG.0000287065.59491.70

Lee, D. T., \& Chung, T. K. (2007). Postnatal depression: An update. Best Practice \& Research Clinical Obstetrics \& Gynaecology, 21(2), 183-191. https://doi.org/10.1016/j.bpobgyn.2006.10.003

Leigh, B., \& Milgrom, J. (2008). Risk factors for antenatal depression, postnatal depression and parenting stress. BMC Psychiatry, 8(1), 24. doi:10.1186/1471-244X-8-24

Marchesi, C., Bertoni, S., \& Maggini, C. (2009). Major and minor depression in pregnancy. Obstetrics \& Gynecology, 113(6), 1292-1298. doi:10.1097/AOG.0b013e3181a45e90

Marino, M., Battaglia, E., Massimino, M., \& Aguglia, E. (2012). Risk factors in post partum depression. Rivista di Psichiatria, 47(3), 187194. doi:10.1708/1128.12439

Matthey, S., Barnett, B., Ungerer, J., \& Waters, B. (2000). Paternal and maternal depressed mood during the transition to parenthood. Journal of Affective Disorders, 60(2), 75-85. https://doi.org/10.1016/S0165-0327(99)00159-7

Moss, K. M., Skouteris, H., Wertheim, E. H., Paxton, S. J., \& Milgrom, J. (2009). Depressive and anxiety symptoms through late pregnancy and the first year post birth: An examination of prospective relationships._Archives of Women's Mental Health,_12(5), 345. doi:10.1007/s00737-009-0086-1

Nanni, V., Uher, R., \& Danese, A. (2012). Childhood maltreatment predicts unfavorable course of illness and treatment outcome in depression: A meta-analysis. American Journal of Psychiatry, 169(2), 141-151. https://doi.org/10.1176/appi.ajp.2011.11020335

Nasreen, H. E., Kabir, Z. N., Forsell, Y., \& Edhborg, M. (2011). Prevalence and associated factors of depressive and anxiety symptoms during pregnancy: A population based study in rural Bangladesh. BMC Women's Health, 11(1), 22. doi:10.1186/1472-6874-11-22

Norman, R. E., Byambaa, M., De, R., Butchart, A., Scott, J., \& Vos, T. (2012). The long-term health consequences of child physical abuse, emotional abuse, and neglect: A systematic review and meta-analysis. PLoS medicine, 9(11), e1001349. https://doi.org/10.1371/journal.pmed.1001349

O’Connor, T. G., Heron, J., Golding, J., Beveridge, M., \& Glover, V. (2002). Maternal antenatal anxiety and children's behavioural/emotional problems at 4 years. The British Journal of Psychiatry, 180(6), 502-508. doi:10.1192/bjp.180.6.502

Ondersma, S. J. (2002). Predictors of neglect within low-SES families: The importance of substance abuse. American Journal of Orthopsychiatry, 72(3), 383-391. doi:10.1037/0002-9432.72.3.383

Paulson, J. F., \& Bazemore, S. D. (2010). Prenatal and postpartum depression in fathers and its association with maternal depression: A meta-analysis. Journal of the American Medical Association, 303(19), 1961-1969. doi:10.1001/jama.2010.605

Paulson, J. F., Bazemore, S. D., Goodman, J. H., \& Leiferman, J. A. (2016). The course and interrelationship of maternal and paternal perinatal depression. Archives of Women's Mental Health, 19(4), 655-663. doi:10.1007/s00737-016-0598-4

Paulson, J. F., Keefe, H. A., \& Leiferman, J. A. (2009). Early parental depression and child language development. Journal of Child Psychology and Psychiatry, 50(3), 254-262. doi:10.1111/j.1469-7610.2008.01973.x

Pawlby, S., Hay, D., Sharp, D., Waters, C. S., \& Pariante, C. M. (2011). Antenatal depression and offspring psychopathology: The influence of childhood maltreatment. The British Journal of Psychiatry, 199, 106-112. doi:10.1192/bjp.bp.110.087734

Pedrabissi, L. \& Santinello, M. (1989). Inventario per l'ansia di stato e di tratto (forma Y). Florence, Italy: Organizzazioni Speciali.

Pereira, P. K., Lovisi, G. M., Pilowsky, D. L., Lima, L. A., \& Legay, L. F. (2009). Depression during pregnancy: Prevalence and risk factors among women attending a public health clinic in Rio de Janeiro, Brazil. Cadernos de Saúde Pública, 25(12), 2725-2736. doi:10.4103/0972-6748.123615

Pines, D. (1972). Pregnancy and motherhood: Interaction between fantasy and reality. Psychology and Psychotherapy: Theory, Research and Practice, 45(4), 333-343. doi:10.1111/j.2044-8341.1972.tb02216.x

Plant, D. T., Pariante, C. M., Sharp, D., \& Pawlby, S. (2015). Maternal depression during pregnancy and offspring depression in adulthood: Role of child maltreatment. The British Journal of Psychiatry, 207(3), 213-220. doi:10.1192/bjp.bp.114.156620

Previti, G., Pawlby, S., Chowdhury, S., Aguglia, E., \& Pariante, C. M. (2014). Neurodevelopmental outcome for offspring of women treated for antenatal depression: A systematic review. Archives of Women's Mental Health, 17(6), 471-483. doi:10.1007/s00737-0140457-0

Ramchandani, P. G., Stein, A., O’Connor, T. G., Heron, J. O. N., Murray, L., \& Evans, J. (2008). Depression in men in the postnatal period and later child psychopathology: A population cohort study. Journal of the American Academy of Child \& Adolescent Psychiatry, 47(4), 390-398. doi:10.1097/CHI.0b013e31816429c2.

Raskin, V. D., Richman, J. A., \& Gaines, C. (1990). Patterns of depressive symptoms in expectant and new parents. The American Journal of Psychiatry, 147(5), 658. doi:10.1176/ajp.147.5.658 


\section{Running head: PSYCHOSOCIAL RISK, ANXIETY, ANTENATAL DEPRESSION}

Robertson, E., Grace, S., Wallington, T., \& Stewart, D. E. (2004). Antenatal risk factors for postpartum depression: A synthesis of recent literature. General Hospital Psychiatry, 26(4), 289-295. doi:10.1016/j.genhosppsych.2004.02.006

Schumacher, M., Zubaran, C., \& White, G. (2008). Bringing birth-related paternal depression to the fore. Women and Birth, 21(2), 65-70. https://doi.org/10.1016/j.wombi.2008.03.008

Sidebottom, A. C., Hellerstedt, W. L., Harrison, P. A., \& Hennrikus, D. (2014). An examination of prenatal and postpartum depressive symptoms among women served by urban community health centers. Archives of Women's Mental Health, 17(1), 27-40. doi:10.1007/s00737-013-0378-3

Spielberger, C. D. (1983). Manual for the State-Trait Anxiety Inventory STAI (form Y)("self-evaluation questionnaire"). Palo Alto, CA: Consulting Psychologists Press.

Staton-Tindall, M., Sprang, G., Clark, J., Walker, R., \& Craig, C. D. (2013). Caregiver substance use and child outcomes: A systematic review. Journal of Social Work Practice in the Addictions, 13(1), 6-31. http://dx.doi.org/10.1080/1533256X.2013.752272

Stein, A., Pearson, R. M., Goodman, S. H., Rapa, E., Rahman, A., McCallum, M., ... Pariante, C. M. (2014). Effects of perinatal mental disorders on the fetus and child. The Lancet, 384(9956), 1800-1819. http://dx.doi.org/10.1016/S0140-6736(14)61277-0

Teixeira, C., Figueiredo, B., Conde, A., Pacheco, A., \& Costa, R. (2009). Anxiety and depression during pregnancy in women and men. Journal of Affective Disorders, 119(1), 142-148. https://doi.org/10.1016/j.jad.2009.03.005

Van den Bergh, B. R., Mennes, M., Oosterlaan, J., Stevens, V., Stiers, P., Marcoen, A., \& Lagae, L. (2005). High antenatal maternal anxiety is related to impulsivity during performance on cognitive tasks in 14- and 15-year-olds. Neuroscience \& Biobehavioral Reviews, 29(2), 259-269. https://doi.org/10.1016/j.neubiorev.2004.10.010

Widom, C. S., DuMont, K., \& Czaja, S. J. (2007). A prospective investigation of major depressive disorder and comorbidity in abused and neglected children grown up. Archives of General Psychiatry, 64(1), 49-56. doi:10.1001/archpsyc.64.1.49

Yanikkerem, E., Ay, S., Mutlu, S., \& Goker, A. (2013). Antenatal depression: Prevalence and risk factors in a hospital based Turkish sample. Journal of Pakistan Medical Association, 63(4), 472-477. Retrieved from http://www.jpma.org.pk/PdfDownload/4116.pdf

Zeng, Y., Cui, Y., \& Li, J. (2015). Prevalence and predictors of antenatal depressive symptoms among Chinese women in their third trimester: A cross-sectional survey. BMC Psychiatry, 15(1), 66. doi:10.1186/s12888-015-0452-7

Zimet, G. D., Dahlem, N. W., Zimet, S. G., \& Farley, G. K. (1988). The multidimensional scale of perceived social support._Journal of Personality Assessment,_52(1), 30-41. http://dx.doi.org/10.1207/s15327752jpa5201_2 
Running head: PSYCHOSOCIAL RISK, ANXIETY, ANTENATAL DEPRESSION

Table 1. Index of social position

\begin{tabular}{|llll|}
\hline \multicolumn{2}{|l}{ Psychosocial variables } & Mothers & Fathers \\
\hline Demographics & Hollingshead's Two & $33.14( \pm 7.82 ;$ & $22.89( \pm 6.43 ;$ \\
& Factor Index of Social Position & range 15.50-48) & range 8.50-40.50) \\
& - Low social position & $37(25.3 \%)$ & $28(26.7 \%)$ \\
$-\quad$ Middle social position & $71(48.6 \%)$ & $63(60 \%)$ \\
& - High social position & $38(26 \%)$ & $14(13.3 \%)$ \\
\hline
\end{tabular}


Running head: PSYCHOSOCIAL RISK, ANXIETY, ANTENATAL DEPRESSION

Table 2. Domains investigated by the Psychosocial Risk Interview

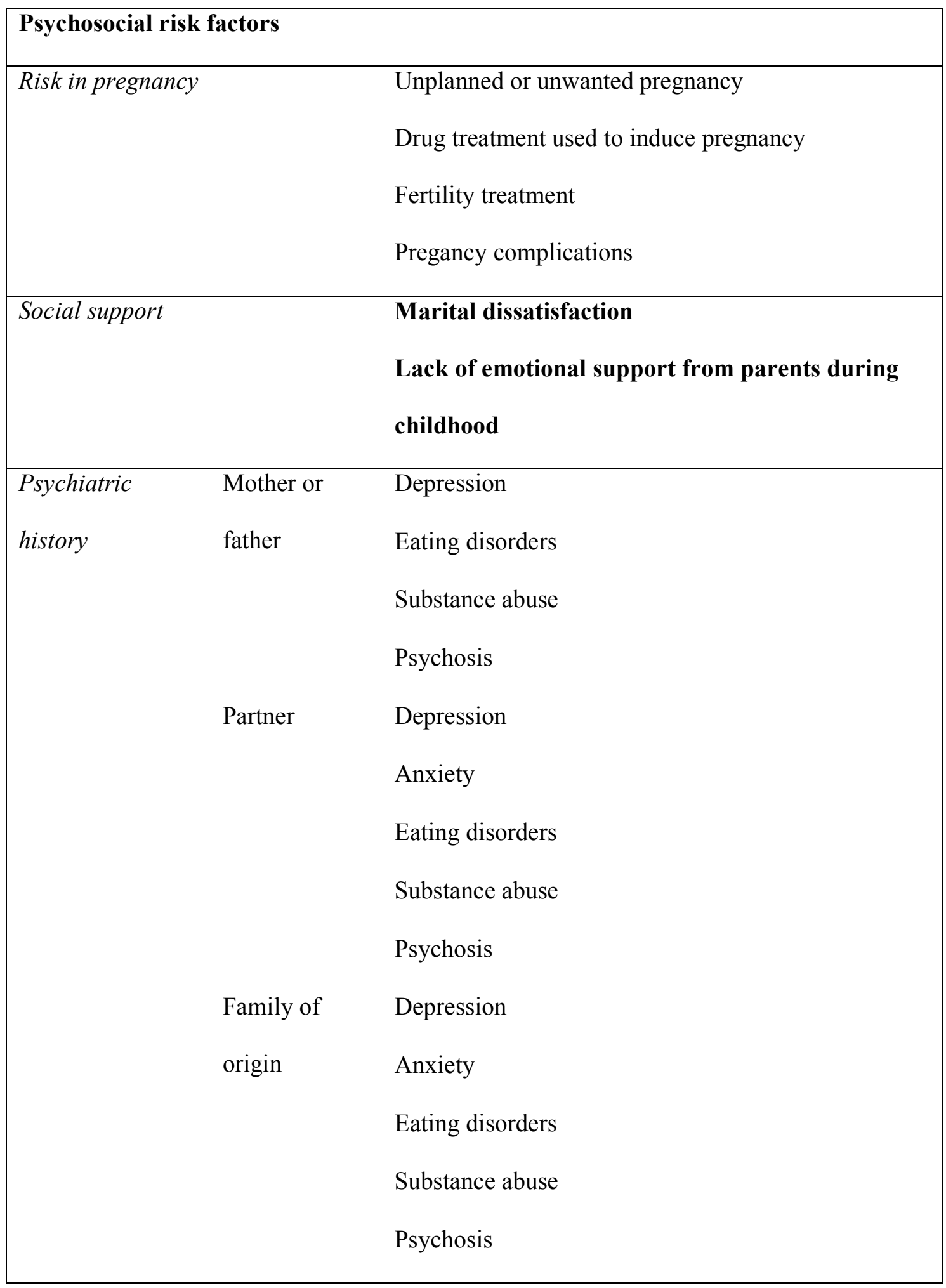


Running head: PSYCHOSOCIAL RISK, ANXIETY, ANTENATAL DEPRESSION

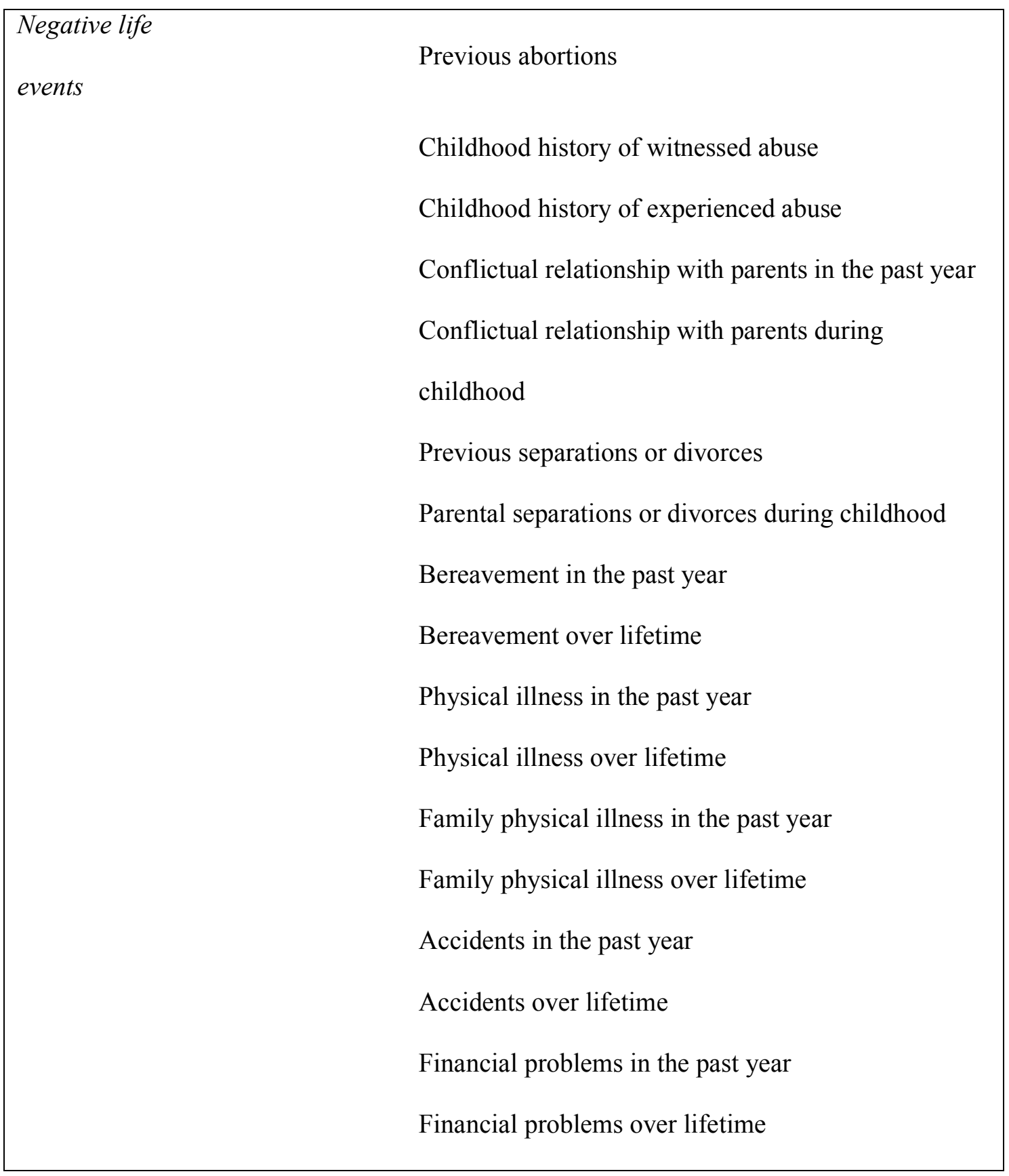


Running head: PSYCHOSOCIAL RISK, ANXIETY, ANTENATAL DEPRESSION

Table 3. Chi square analysis to explore the relationship between psychosocial independent (categorical) variables and depressive

symptomatology, in mothers

\begin{tabular}{|c|c|c|c|c|c|c|c|c|c|c|}
\hline \multirow{3}{*}{ Psychosocial risk factors } & \multicolumn{4}{|c|}{ Depressive symptomatology } & \multicolumn{4}{|c|}{ Without depressive symptomatology } & \multirow{3}{*}{$\mathrm{Chi}^{2}$} & \multirow{3}{*}{$\mathbf{p}$} \\
\hline & \multicolumn{2}{|c|}{ Yes } & \multicolumn{2}{|l|}{ No } & \multicolumn{2}{|l|}{ Yes } & \multicolumn{2}{|l|}{ No } & & \\
\hline & $\mathbf{N}(\%)$ & $\mathbf{S r}$ & $\mathbf{N}(\%)$ & $\mathrm{Sr}$ & $\mathbf{N}(\%)$ & sr & $\mathbf{N}(\%)$ & $\mathrm{Sr}$ & & \\
\hline $\begin{array}{l}\text { Risk in pregnancy } \\
\text { Unplanned or unwanted } \\
\text { pregnancy }\end{array}$ & $8(17.8 \%)$ & 2.2 & $37(82.2 \%)$ & -.7 & $4(4 \%)$ & -1.5 & $97(96 \%)$ & .4 & 7.879 & .008 \\
\hline Social support & & & & & & & & & & \\
\hline Marital dissatisfaction & $22(48.9 \%)$ & 4.9 & $23(51.1 \%)$ & -2.3 & $4(4 \%)$ & -3.3 & $97(96 \%)$ & 1.5 & 42.931 & .000 \\
\hline Psychiatric history & & & & & & & & & & \\
\hline Personal history of depression & $14(31.1 \%)$ & 2.3 & $31(37.3 \%)$ & -1 & $11(10.9 \%)$ & -1.5 & $90(89.1 \%)$ & .7 & 8.969 & .003 \\
\hline $\begin{array}{l}\text { Family history of substance } \\
\text { abuse }\end{array}$ & $7(15.6 \%)$ & 2 & $38(84.4 \%)$ & -.6 & $4(4 \%)$ & -1.3 & $97(96 \%)$ & .4 & 6.008 & .014 \\
\hline Negative life events & & & & & & & & & & \\
\hline
\end{tabular}


Running head: PSYCHOSOCIAL RISK, ANXIETY, ANTENATAL DEPRESSION

\begin{tabular}{|c|c|c|c|c|c|c|c|c|c|c|}
\hline $\begin{array}{l}\text { Conflictual relationship with } \\
\text { parents in the past year }\end{array}$ & $16(35.6 \%)$ & 1.3 & $29(64.4 \%)$ & -1.2 & $8(7.9 \%)$ & -2.1 & $93(92.1 \%)$ & .9 & 17.307 & .000 \\
\hline $\begin{array}{l}\text { Parental separation during } \\
\text { childhood }\end{array}$ & $14(31.1 \%)$ & 1.8 & $31(68.9 \%)$ & -.9 & $14(13.9 \%)$ & -1.2 & $87(86.1 \%)$ & .6 & 5.976 & .015 \\
\hline Bereavement in the past year & $11(24.4 \% 9$ & 1.9 & $34(75.6 \%)$ & -.8 & $9(8.9 \%)$ & -1.3 & $92(91.1 \%)$ & .5 & 6.354 & .012 \\
\hline
\end{tabular}


Running head: PSYCHOSOCIAL RISK, ANXIETY, ANTENATAL DEPRESSION

Table 4. Chi square analysis to explore the relationship between psychosocial independent (categorical) variables and depressive symptomatology, in fathers

\begin{tabular}{|c|c|c|c|c|c|c|c|c|c|c|}
\hline \multirow{3}{*}{ Psychosocial risk factors } & \multicolumn{4}{|c|}{ Depressive symptomatology } & \multicolumn{6}{|c|}{ Without depressive symptomatology } \\
\hline & \multicolumn{2}{|c|}{ Yes } & \multicolumn{2}{|l|}{ No } & \multicolumn{2}{|l|}{ Yes } & \multicolumn{2}{|l|}{ No } & \multirow[t]{2}{*}{$\mathrm{Chi}^{2}$} & \multirow[t]{2}{*}{$\mathbf{p}$} \\
\hline & $\mathbf{N}(\%)$ & $\mathrm{Sr}$ & $\mathbf{N}(\%)$ & $\mathrm{Sr}$ & $\mathbf{N}(\%)$ & $\mathbf{S r}$ & $\mathbf{N}(\%)$ & $\mathbf{S r}$ & & \\
\hline \multicolumn{11}{|l|}{ Social support } \\
\hline Marital dissatisfaction & $7(38.9 \%)$ & 1.9 & $11(61.1 \%)$ & .4 & $13(14.9 \%)$ & -1 & $74(85.1 \%)$ & .4 & 5.546 & .027 \\
\hline \multicolumn{11}{|l|}{ Psychiatric history } \\
\hline Personal history of depression & $6(33.3 \%)$ & 2.1 & $12(66.7 \%)$ & -.9 & $9(10.3)$ & -1 & $78(89.7 \%)$ & .4 & 6.437 & .011 \\
\hline Partner's history of depression & $6(33.3 \%)$ & 3.6 & $12(66.7 \%)$ & -1.1 & $3(3.4 \%)$ & -1.6 & $84(96.6 \%)$ & .5 & 16.997 & .001 \\
\hline Partner's history of anxiety & $7(38.9 \%)$ & 1.9 & $11(61.1 \%)$ & -.9 & $13(14.9 \%)$ & -.9 & $74(85.1 \%)$ & .4 & 5.546 & .019 \\
\hline
\end{tabular}


Running head: PSYCHOSOCIAL RISK, ANXIETY, ANTENATAL DEPRESSION

Table 5. Correlation between psychosocial independent (continuous) variables and depressive symptomatology, in mothers and in fathers

\begin{tabular}{|l|c|c|}
\hline \multirow{2}{*}{ Independent variables } & \multicolumn{2}{|c|}{ EPDS } \\
\cline { 2 - 4 } & Mothers & Fathers \\
\hline Age & & \\
Hollingshead's Two Factor Index of Social Position & -.055 & .089 \\
\hline Perceived social support & & \\
MPSS & $-.308^{* *}$ & $-.339^{* *}$ \\
\hline Personal trait anxiety & & \\
STAI & .025 \\
\hline
\end{tabular}

$* * p<0.01$ 
Running head: PSYCHOSOCIAL RISK, ANXIETY, ANTENATAL DEPRESSION

Table 6. Hierarchical regression for predictors of antenatal depressive symptomatology, in mothers

\begin{tabular}{|c|c|c|c|c|c|c|}
\hline Predictors & & B & SE & $\boldsymbol{\beta}$ & $\mathbf{T}$ & $\mathbf{p}$ \\
\hline \multicolumn{7}{|l|}{ Model 1} \\
\hline \multirow[t]{2}{*}{ Demographics } & Age & -.20 & .07 & -.23 & -2.829 & .005 \\
\hline & $R^{2}=.05 ;$ Adjusted $R^{2}=.05 ; F_{(1.144)}=8.004 ; p=.005$ & & & & & \\
\hline \multicolumn{7}{|l|}{ Model 2} \\
\hline Demographics & Age & -.16 & .07 & -.19 & -2.278 & .024 \\
\hline \multirow[t]{2}{*}{ Pregnancy risk factors } & Unplanned or unwanted pregnancy & 3.37 & 1.28 & .21 & 2.639 & .009 \\
\hline & $R^{2}=.10 ;$ Adjusted $R^{2}=.10 ; R^{2}$ change $=.04 ; F_{(2.143)}=7.649 ; p=.001$ & & & & & \\
\hline \multicolumn{7}{|l|}{ Model 3} \\
\hline Demographics & Age & -.15 & .07 & -.17 & -2.314 & .022 \\
\hline Pregnancy risk factors & Unplanned or unwanted pregnancy & 1.40 & 1.22 & .09 & 1.145 & .254 \\
\hline \multirow[t]{3}{*}{ Social support } & Marital dissatisfaction & 3.58 & .89 & .32 & 4.030 & .000 \\
\hline & Perceived social support (MPSS) & -.92 & .31 & -.22 & -2.972 & .003 \\
\hline & $R^{2}=.27 ;$ Adjusted $R^{2}=.25 ; R^{2}$ change $=.17 ; F_{(4.141)}=12.734 ; p=.000$. & & & & & \\
\hline
\end{tabular}


Running head: PSYCHOSOCIAL RISK, ANXIETY, ANTENATAL DEPRESSION

\begin{tabular}{|c|c|c|c|c|c|c|}
\hline Demographics & Age & -.07 & .05 & -.08 & -1.395 & .165 \\
\hline Pregnancy risk factors & Unplanned or unwanted pregnancy & -.28 & .99 & -.02 & -.278 & .781 \\
\hline \multirow[t]{2}{*}{ Social support } & Marital dissatisfaction & 3.14 & .72 & .28 & 4.389 & .000 \\
\hline & Perceived social support (MPSS) & -.33 & .26 & -.08 & -1.274 & .205 \\
\hline \multirow[t]{4}{*}{ Psychopathology } & Personal history of depression & 1.79 & .70 & .16 & 2.573 & .011 \\
\hline & Personal trait anxiety (STAI) & .27 & .04 & .46 & 7.238 & .000 \\
\hline & Family history of substance abuse & 2.54 & .99 & .16 & 2.572 & .011 \\
\hline & $R^{2}=.54 ;$ Adjusted $R^{2}=.52 ; R^{2}$ change $=.28 ; F_{(7.138)}=23.150 ; p=.000$ & & & & & \\
\hline \multicolumn{7}{|l|}{ Model 5} \\
\hline Demographics & Age & -.07 & .05 & -.08 & -1.365 & .174 \\
\hline Pregnancy risk factors & Unplanned or unwanted pregnancy & -.12 & .96 & -.01 & -.126 & .900 \\
\hline \multirow[t]{2}{*}{ Social support } & Marital dissatisfaction & 2.62 & .70 & .23 & 3.758 & .000 \\
\hline & Perceived social support (MPSS) & -.31 & .25 & -.08 & -1.238 & .218 \\
\hline \multirow[t]{3}{*}{ Psychopathology } & Personal history of depression & 1.47 & .68 & .13 & 2.159 & .033 \\
\hline & Personal trait anxiety (STAI) & .26 & .04 & .45 & 7.314 & .000 \\
\hline & Family history of substance abuse & 2.37 & .96 & .15 & 2.461 & .015 \\
\hline
\end{tabular}


Running head: PSYCHOSOCIAL RISK, ANXIETY, ANTENATAL DEPRESSION

Negative life events

Conflictual relationship with parents in the past year

1.94

Parental separation during childhood

Loss in the past year

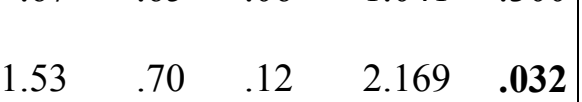

$R^{2}=.59 ;$ Adjusted $R^{2}=.56 ; R^{2}$ change $=.05 ; F_{(10.135)}=19.928 ; p=.000$. 
Running head: PSYCHOSOCIAL RISK, ANXIETY, ANTENATAL DEPRESSION

Table 7. Hierarchical regression for predictors of antenatal depressive symptomatology, in fathers

\begin{tabular}{|c|c|c|c|c|c|c|}
\hline Predictors & & $\mathbf{B}$ & SE & $\boldsymbol{\beta}$ & $\mathbf{T}$ & $\mathbf{p}$ \\
\hline \multicolumn{7}{|l|}{ Model 1} \\
\hline \multirow[t]{3}{*}{ Social support } & Marital dissatisfaction & 2.75 & .92 & .29 & 3.001 & .003 \\
\hline & Perceived social support (MPSS) & -.73 & .32 & -.22 & -2.272 & .025 \\
\hline & \multicolumn{6}{|c|}{$R^{2}=.19 ;$ Adjusted $R^{2}=.17 ; F_{(2.103)}=11.721 ; p=.000$} \\
\hline \multicolumn{7}{|l|}{ Model 2} \\
\hline \multirow[t]{2}{*}{ Social support } & Marital dissatisfaction & 1.75 & .82 & .19 & 2.143 & .035 \\
\hline & Perceived social support (MPSS) & -.29 & .30 & -.09 & -.988 & .325 \\
\hline \multirow[t]{5}{*}{ Psychiatric history } & Personal history of depression & 1.83 & .87 & .17 & 2.108 & .038 \\
\hline & Personal trait anxiety (STAI) & .21 & .05 & .37 & 4.324 & .000 \\
\hline & Partner's history of depression & 1.80 & 1.11 & .14 & 1.620 & .108 \\
\hline & Partner's history of anxiety & .60 & .80 & .06 & .752 & .454 \\
\hline & \multicolumn{6}{|c|}{$R^{2}=.42 ;$ Adjusted $R^{2}=.38 ; R^{2}$ change $=.23 ; F_{(6.99)}=11.808 ; p=.000}$. \\
\hline
\end{tabular}

